\title{
Size contrast as a function of conceptual similarity between test and inducers
}

\author{
STANLEY COREN and JAMES T. ENNS \\ University of British Columbia, Vancouver, British Columbia, Canada
}

\begin{abstract}
In four experiments, the effect of the semantic relationship between test and inducing stimuli on the magnitude of size contrast in an Ebbinghaus-type illusion was explored. In Experiments 1 and 2, the greatest illusion was found when test and inducing stimuli were identical in shape and differed only in size. Decreased size contrast was found when inducing stimuli were drawn from the same category as the test stimulus, but were not visually identical. Even less size contrast was found when inducing stimuli were from a near conceptual category, with the least effect when they were drawn from a completely different category. In Experiment 3, it was demonstrated that even if test and inducing stimuli are drawn with identical geometric elements, the size contrast illusion is greatly reduced if they represent apparently different conceptual categories (through the manipulation of orientation and perceptual set). In Experiment 4, any geometric or spatial confounds were ruled out. These results suggest that size contrast is strongly influenced by the conceptual similarity between test and inducing stimuli.
\end{abstract}

Contrast was the term introduced by Helmholtz (1866) to explain perceptual distortions associated with the exaggeration of clearly perceived sensory differences. This concept was later elaborated by Wundt (1894), who called it the law of perceptual relativity. Contrast can be shown for many sensory continua. At the sensory level we find brightness and color contrast. Higher level contrast effects can be found for size, shape, and direction (see Coren \& Girgus, 1978). A commonly encountered example of size contrast occurs when a 5 - $\mathrm{ft} 10$-in. sports announcer appears to be much shorter than average when interviewing a group of basketball players, but taller than average when interviewing a group of racehorse jockeys.

Contemporary explanations of size contrast are based upon the same notions that underlie Helson's (1964) adaptation level theory. This theory, and its many elaborations, makes the assumption that the sensory magnitude of any stimulus is judged in a relative way, using the magnitude of the surrounding context stimuli as a reference. This conception can be used to explain a number of visual illusions, given appropriate viewing conditions (e.g., Girgus \& Coren, 1982; Jordan \& Schiano, 1986; Jordan \& Uhlarik, 1986; Wilson \& Pressey, 1988).

The visual illusion that is usually taken as the prototype for size contrast effects is the Ebbinghaus illusion (Figure 1A), in which a central circle surrounded by large

This research was supported by grants from the Natural Sciences and Engineering Research Council of Canada. We would like to acknowledge the assistance of Joan Coren, David Wong, Wayne Wong, Lynda Berger, and Geof Donelly, who assisted in stimulus preparation and scoring of these data. For reprints or other correspondence, contact S. Coren, Department of Psychology, University of British Columbia, 2136 West Mall, Vancouver, B.C., Canada, V6T 1ZA. Phone (604) 822-6458. Fax (604) 822-6923. inducing elements appears to be smaller than a same-size central circle surrounded by smaller elements. Parametric manipulations of inducing-circle size show that the effects are systematically dependent upon the size of the surrounding elements (Coren \& Girgus, 1978; Girgus, Coren, \& Agdern, 1972; Massaro \& Anderson, 1971; Weintraub \& Schneck, 1986).

There is evidence suggesting that size contrast effects are due to active cognitive comparative processes rather than peripheral physiological factors. The contour interaction processes, which appear to contribute to many illusions, seem to have been ruled out for the Ebbinghaus illusion. This is confirmed by the fact that increases in optical blur do not affect the strength of the illusion (Coren \& Porac, 1978a; Coren, Ward, Porac, \& Fraser, 1978), nor do variations in lateral inhibitory interactions (Coren \& Aks, 1990). The existence of cognitive contributions to the Ebbinghaus illusion was confirmed by Coren (1971), who provided a demonstration that showed that it is the apparent size of the inducing stimuli, not the size of the stimuli in the retinal image, that sustains size contrast. In his study, inducing stimuli that varied in size only because of size constancy still triggered the contrast mechanism. This finding suggests a comparison process occurring at a fairly high level. Other findings that support this conclusion are observations that direct manipulations of the observer's distribution of attention to the inducers, without any change in the retinal pattern, affect the magnitude of size contrast in various situations (Jordan \& English, 1989; Restle, 1971; Shulman, 1991).

Although size contrast is well known, and is accepted as a mechanism for many perceptual phenomena, there have been few studies that have examined the factors that control it or the conditions under which it is evoked. At the purely descriptive level, we can return to the exam- 

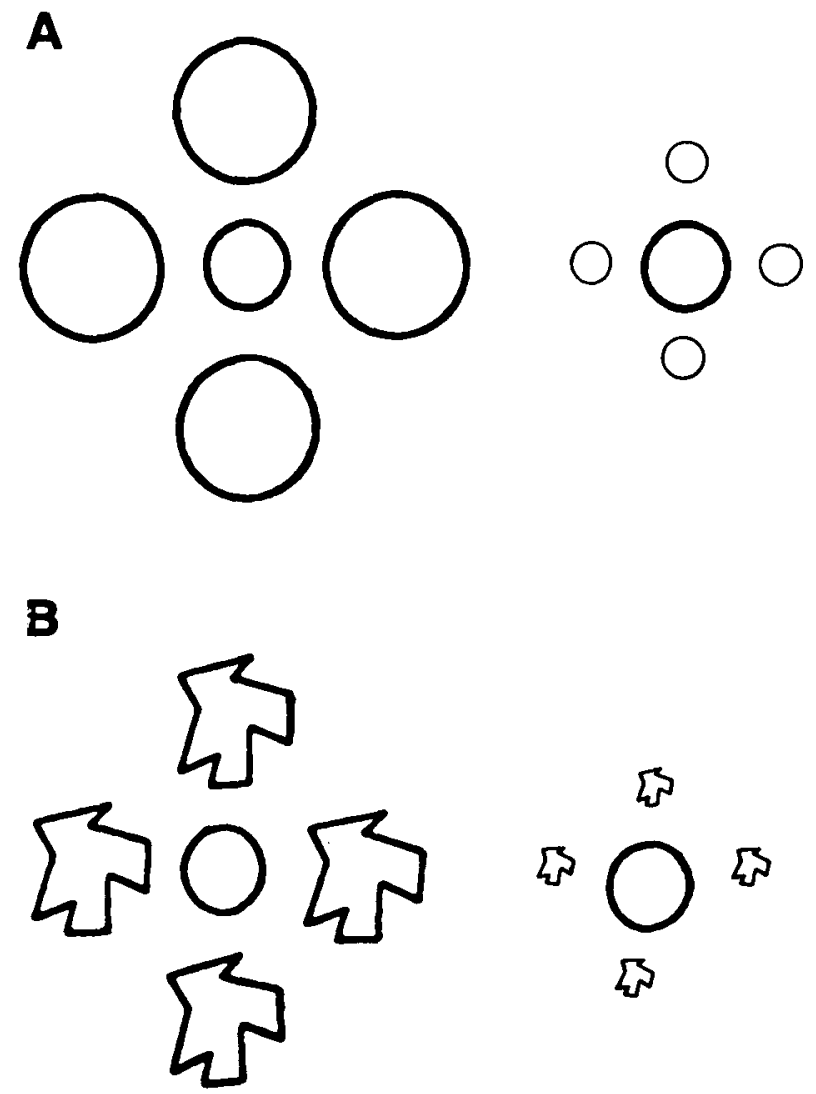

Figure 1. (A) Size contrast illustrated in the standard Ebbinghaus illusion, in which the circle surrounded by large inducing circles appears smaller than the circle surrounded by smaller inducers. (B) $A$ variant of the Ebbinghaus illusion in which the inducers are visually quite different from the central circle, producing a much-reduced illusion (after Coren \& Miller, 1974).

ple of the sports announcer mentioned earlier. Although he appears larger or smaller in the context of larger or smaller men, we certainly would not expect him to shrink in apparent size when the sound level produced by the noise of spectators increases. This suggests that contrast comparisons must remain within the same stimulus modality. Furthermore, when standing beside a large racehorse, or in the middle of a large stadium, we would also not expect his apparent size to change very much.

Coren and Miller (1974) suggested that a critical factor involved in size contrast is the perceived similarity between the test item and the context in which it is embedded. In their study, they used versions of the Ebbinghaus illusion in which the inducers varied systematically from the test element in their perceived (visual-geometric) similarity. Using the Ebbinghaus illusion as their model, they were able to show that when the inducers looked very different from the central test stimulus, as in Figure 1B, the magnitude of the size contrast effect was greatly attenuated.

Geometric similarity seems to be a useful dimension involved in the control of size contrast, but it may reflect only a limited aspect of the actual mechanism that serves to trigger contrast. In Figure 1A, the inducers are clearly drawn from the same conceptual class as the test element (e.g., symmetrical figures or, more specifically, circles). In Figure $1 \mathrm{~B}$, the inducing figures not only differ visually from the central test element, but also differ from the circular test object at some conceptual levels. For instance, the inducers in Figure 1B no longer can be classified in the category of "circles," nor could they be considered as exemplars of the familiar set of commonly encountered regular figures to which circles belong. Thus, it may well be the case that the randomly shaped surrounding figures are actually viewed as having been drawn from a different semantic category, and hence are not contrasted against the test element because of this difference in category membership rather than simply because of considerations of visual similarity. In our previous example, this would be equivalent to surrounding the sports announcer with young school boys instead of racehorse jockeys. In that case, although the size differential remained, it may be that the size contrast effect would not be as marked, because the comparison involved an adult male as the test element and individuals in a different conceptual category (male children) as the inducing elements. Casual observation certainly suggests that size contrast would not be as strong.

Although we are unaware of any previous direct tests of this hypothesis, there are several lines of research that suggest that size judgments might very well be influenced by the conceptual relatedness of the test and inducing elements. Before singling out size as an attribute, let us recall that picture-naming tasks have shown repeatedly that the processing of a picture is often influenced by the conceptual relatedness of other pictures and words in the nearby spatiotemporal context (La Heij \& Dirkx, 1990). In a standard priming paradigm, in which a to-be-named picture (target) has been preceded by another picture or word (prime), the latency to name the target is directly related to the semantic distance between prime and target objects (Irwin \& Lupker, 1983; Lupker, 1979, 1988; Sperber, McCauley, Ragain, \& Weil, 1979). In a Stroop paradigm, in which a to-be-named picture (target) is presented simultaneously with a printed word (distractor), the latency to name the target is related to the conceptual similarity between the target and the distractor $(\mathrm{La} \mathrm{Heij}$, 1988; Posnansky \& Rayner, 1977; Rayner \& Springer, 1986; Rosinski, 1975). Finally, in a negative priming paradigm, in which one of two overlapping pictures is named on each trial, latency to name the picture is predicted by its conceptual similarity to the picture that was ignored on the previous trial (Tipper, 1985; Tipper \& Driver, 1988).

Although the above studies examined the effects of conceptual similarity on figure identification in general, several studies have extended this mode of analysis to incorporate the size dimension. These involve the mental comparison of various object attributes (Foltz \& Poltrock, 1984; Marshark \& Paivio, 1981). For instance, when subjects are asked to make relative size judgments of two 
words ("which object is larger?"), they are able to do so more quickly for pairs of objects that are semantically related than for pairs that are unrelated (Holyoak, Dumais, \& Moyer, 1979). Interestingly for the present hypothesis, the advantage of semantic relatedness in this task is even greater when the size differences between the objects to be compared are small rather than large. It is almost as though small size differences between semantically similar objects are subjectively enlarged compared with the same small differences between dissimilar objects. Such results certainly suggest that size comparisons (and hence, perhaps, size contrast effects) are more easily triggered in objects that fall into the same conceptual category.

Both the informal observations of size comparisons noted above and extrapolations from the attribute comparison studies suggest that we might expect size contrast to be influenced by the semantic category membership of the items to be compared. Specifically, the relationship between the test and the inducing stimuli might be expected to influence the magnitude of the size contrast illusion. The following set of studies was designed to test this hypothesis.

\section{EXPERIMENT 1}

\section{Method}

Stimuli. To create a series of Ebbinghaus illusion figures in which category membership could be varied, the use of meaningful objects as both test and inducing elements was required. Figure 2 shows a typical set of stimuli in which, instead of using simple geometric figures, the prototype is a line drawing of a dog. Surrounding the prototype are exact copies of the test item, differing only in size. Notice that the usual size contrast effect appears in this stimulus. We call this condition the prototype condition, because the test and inducing stimuli are identical in all aspects other than size.

Next, we need inducing stimuli that are drawn from the same conceptual category but are visually different from the test element. An example of this can be seen in Figure $3 \mathrm{~A}$ with dog as the test element and in Figure 3B with girl's head as the test element. No- tice that in Figure 3A, each of the individual dogs differs in breed and the orientations vary from the prototype. For the girls' heads, the faces and hairstyles vary and there is also some variation in orientation. Although only the large inducers are shown here, the smaller inducers were identical to these, differing only in size.

An example of stimuli drawn from near conceptual categories are shown in Figures 3C and 3D. For the dog, horses in different orientations served as the near stimulus category (e.g., four-footed domestic animals). For the girl's head, a set of four different adult male heads served as the near category (e.g., human heads).

Finally, examples of inducers drawn from different conceptual categories are shown in Figures $3 \mathrm{E}$ and $3 \mathrm{~F}$. For the dog test element, the inducers were pairs of shoes and for the girl's head, the inducers were trucks.

A total of eight sets of stimuli were prepared. Table 1 lists the prototype (central test element for each set), as well as the stimuli from same, near, and different conceptual categories. The maximum horizontal extent of the test stimulus was $22 \mathrm{~mm}$. The corresponding extent for the large inducer was $40 \mathrm{~mm}$, and for the small was $10 \mathrm{~mm}$. The stimuli were prepared in booklets, each one containing only one prototype, with all four categories of inducers. Each page of the booklet consisted of a single stimulus configuration (test element with large or small inducers).

In addition to the size contrast stimuli, four practice stimuli were prepared for each stimulus set. The practice stimuli matched the prototype, but without any inducers. The four practice stimuli were $18,22,26$, and $30 \mathrm{~mm}$ in horizontal dimension. The purpose of the practice stimuli was to ensure that the subject had understood the instructions and was responding in a reasonably accurate manner.

Procedure. Each subject received only one series of stimuli (all variations associated with a particular prototype). Following the four practice stimuli, each of the size contrast configurations was presented in a random order.

Judgments were made using a graded series procedure in which the subjects selected from a series of 15 figures that were identical to the prototype in shape, but varied in size. The size varied in 1$\mathrm{mm}$ steps from 16 to $30 \mathrm{~mm}$, with each figure numbered. Coren and Girgus (1972) have shown that this method of illusion measurement is as accurate as the method of average error and is suitable for group assessment. It has been successfully used to measure several size illusions, including the Müller-Lyer illusion (Porac \& Coren, 1981), the Ebbinghaus illusion (Coren \& Porac, 1978a, 1978b), the pictorial moon illusion (Coren \& Aks, 1990), and even a tilt illusion (Coren \& Hoy, 1986).
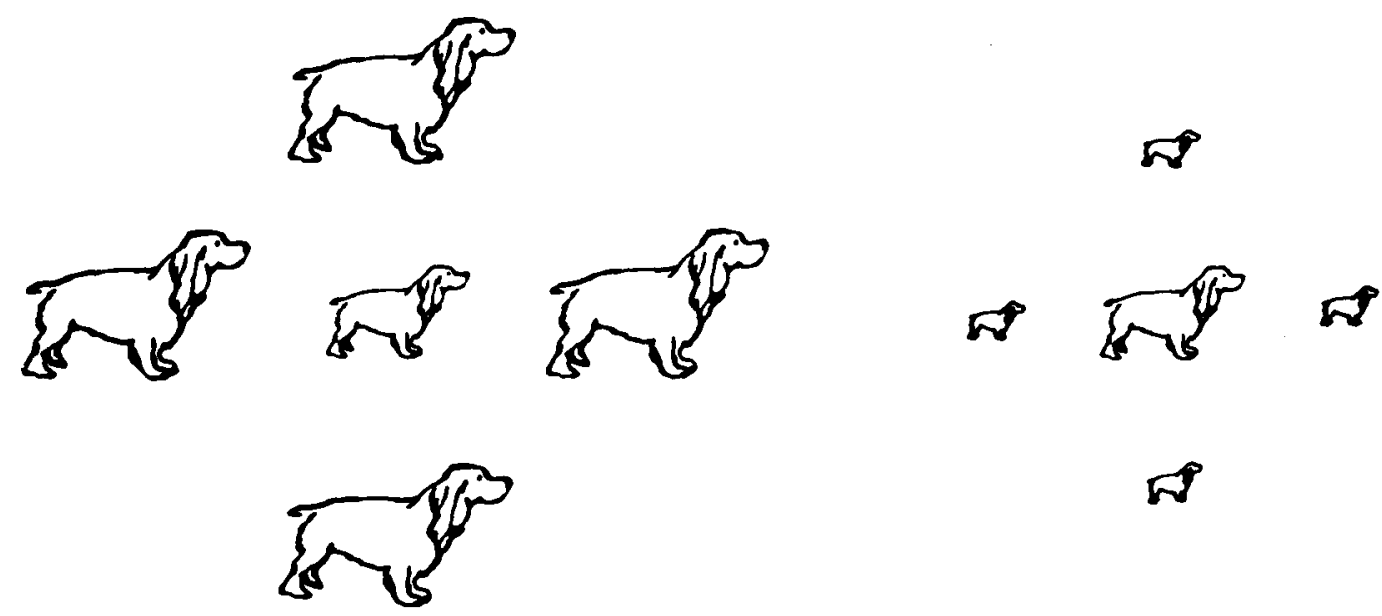

Figure 2. The prototype variant of the Ebbinghaus illusion in which both test and inducers are objects that are visually identical, differing only in size. 


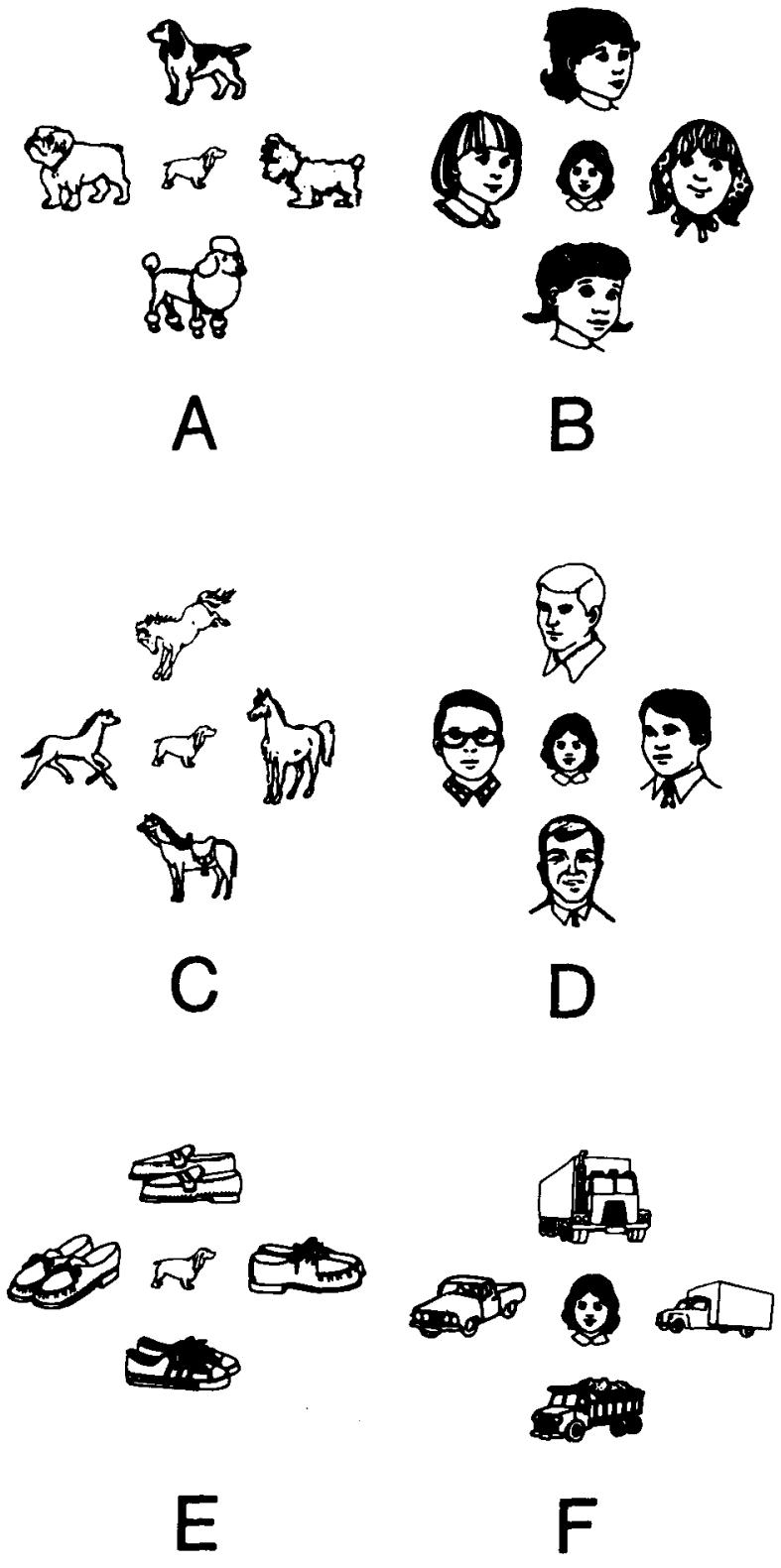

Figure 3. Panels $A$ and $B$ represent configurations in which test and inducers are drawn from the same conceptual categories, and Panels $C$ and $D$ are configurations in which test and inducers are drawn from a near or related (although not the same) conceptual category. In Panels $\mathbf{E}$ and $F$, the inducers and test element are drawn from quite different categories.

Subjects. The subjects were 118 undergraduate student volunteers who were assessed in group settings. Mean age was 18.4 years. All the subjects were naive as to the purpose of the experiment. Prior to the scoring of the illusion magnitudes, the subjects were scored on the accuracy of their settings on the four practice figures. Those who had a mean absolute deviation of more than $1.5 \mathrm{~mm}$ from the actual size of the practice figures were discarded from the sample without further consideration. This left a final subject sample size of 107 individuals.

\section{Results and Discussion}

The results of Experiment 1 are shown in Figure 4. In all four stimulus types there was the expected size contrast illusion, with the test elements surrounded by large items judged as smaller than the equivalent test elements surrounded by small items. This difference in judged size was significant at $p<.01$ for each of the four stimulus types, regardless of category membership $[t(106)=6.69$, $t(106)=5.17, t(106)=4.46$, and $t(106)=2.62$, for prototype and same-, near-, and far-category inducers, respectively]. This demonstrates that size contrast was obtained in all cases.

When we look at the effects of category membership on the magnitude of the illusion, however, there are clear influences resulting from the relationship between test and inducing stimuli. As can be seen from Figure 4, the largest illusion magnitude was for the prototype condition, in which the test element was surrounded by inducers that were identical in shape, differing only in size. The smallest illusion was found for the condition in which the inducers were drawn from a conceptually different category. An analysis of variance (ANOVA) confirmed that there were significant differences among the illusion types $[F(3,318)=$ $2.87, p<.05]$.

When individual planned comparisons were conducted among the various conditions, the only significant paired differences were between the prototype and the different category conditions $[t(106)=2.87, p<.01]$ and the same-category versus different-category inducers $[t(106)=2.17, p<.05]$. However, a trend analysis showed a significant linear component for decreasing illusion magnitude as the difference between the inducer and the test element increased $[F(1,318)=6.86, p<$ $.01]$. It may be argued that a trend analysis was inappropriate, because we could not be sure that the similarity differences were equally spaced between conditions. For this reason, the Kendall coefficient of concordance was used to look at the consistency of the rank ordering of the illusion magnitudes across the four conditions. This confirmed a consistent ordering, with diminishing illusion magnitude as the difference in conceptual distance between inducers and test stimuli grew larger $[W=.04$, $\left.\chi^{2}(3)=12.55, p<.01\right]$.

The present findings were generally in the expected direction predicted by the hypothesis-that the magnitude of size contrast effects are determined in part by the similarity of the test and inducing stimuli in terms of conceptual category membership. Although the results were generally as predicted, the rank ordering was not perfectly in accord with the theory because the same and near categories gave approximately the same illusion magnitude. This outcome, however, may simply reflect the fact that the measured illusion magnitude was small; hence, there was little room for the conditions to separate themselves. Generally speaking, size contrast illusions tend to be small in magnitude. The magnitude of the prototype illusion ob- 
Table 1

\begin{tabular}{|c|c|c|c|}
\hline \multirow[b]{2}{*}{ Prototype } & \multicolumn{3}{|c|}{ Inducing Stimuli } \\
\hline & Same Category & Near Category & Different Category \\
\hline & $\begin{array}{l}\text { Different } \\
\text { breeds of dog }\end{array}$ & Horses & Shoes \\
\hline orse & $\begin{array}{l}\text { Horses in } \\
\text { different poses }\end{array}$ & Dogs & Men's faces \\
\hline Man's face & $\begin{array}{l}\text { Different men's } \\
\text { faces }\end{array}$ & Girls' faces & Women's handbags \\
\hline Girl's face & $\begin{array}{l}\text { Different girls' } \\
\text { faces }\end{array}$ & Men's faces & Trucks \\
\hline utomobiles & $\begin{array}{l}\text { Automobiles of } \\
\text { different makes } \\
\text { and orientation }\end{array}$ & Trucks & Girls' faces \\
\hline rucks & $\begin{array}{l}\text { Different types } \\
\text { of trucks }\end{array}$ & Automobiles & Dogs \\
\hline Vomen's handbags & $\begin{array}{l}\text { Different types } \\
\text { of handbags }\end{array}$ & Shoes & Horses \\
\hline loes & $\begin{array}{l}\text { Different types } \\
\text { of shoes }\end{array}$ & Women's handbags & Automobiles \\
\hline
\end{tabular}

tained here was $0.8 \mathrm{~mm}$ (albeit with a standard error of only $0.11 \mathrm{~mm}$ ). Although small when measured in number of millimeters, this illusion magnitude in percentage terms amounts to a $3.6 \%$ distortion. This is comparable to the size of the illusion obtained in other studies that have used Ebbinghaus-type stimuli and a similar gradedseries measurement technique (e.g., Coren \& Girgus, 1972; Coren \& Porac, 1978a, 1978b). Nonetheless, it is possible that a measurement technique that allowed more variation in the illusion magnitude might be expected to show larger variation between conditions.

It has been shown that the measured magnitude of an illusory distortion may be attenuated if the matching stimulus is identical in shape to the test element (Coren \& Aks, 1990; Wallach \& Floor, 1971). The solution to this problem has been to use a comparison stimulus of a different shape, thereby requiring subjects to judge only the size of one aspect (or dimension) of the test stimulus.

One technique for doing this is called the method of reproduction (Coren \& Girgus, 1972). For linear arrays, this simply involves a horizontal line on which an extent equal to that perceived in some designated aspect of the test stimulus is marked off. For example, in measuring the perceived size of a circular element, one might ask the subject to mark off the extent equal to the diameter. This procedure has been used to measure illusion magnitude in a number of different configurations, by specifying aspects of the distortion that could be encoded as a simply judged linear extent (e.g., Coren, Girgus, Erlichman, \& Hakstian, 1976; Porac, Coren, Girgus, \& Verde, 1979). Coren and Girgus (1972) also observed greater illusion magnitude for the method of reproduction as compared with selection from a graded series in both the Müller-Lyer and Ebbinghaus illusions, whereas Coren and
Aks (1990) report similar results for a pictorial version of the moon illusion. Therefore, we decided to conduct an experiment similar to Experiment 1, using the method of reproduction instead of matching to a graded series. An added benefit of using another measure was that it provided an independent opportunity to replicate the conceptual category effect that we had already observed.

\section{EXPERIMENT 2}

\section{Method}

Stimuli. The same stimulus set and method of preparation used in Experiment 1 were employed. The only difference was that a measurement line $85 \mathrm{~mm}$ in length and $3 \mathrm{~mm}$ wide, with a $10-\mathrm{mm}$ vertical stop at the far left end, was provided on each page. The



Figure 4. Data from Experiment 1 (using selection from a graded series) showing the magnitude of the size contrast illusion as a function of the degree of conceptual similarity between test and inducing stimuli. Illusion magnitude is defined as the difference between two judged extents: the test stimulus surrounded by small inducers versus the same-size test stimulus surrounded by large inducers. 
line was placed $1 \mathrm{~cm}$ from the bottom edge of the sheet containing each test stimulus and $15 \mathrm{~mm}$ from the left edge.

Procedure. The procedure was similar to that of Experiment 1, except that the subjects were instructed to indicate the widest horizontal extent of each test figure. This was done by placing a pencil tick mark, so that the distance between the left end of the line (which contained the vertical stop) and the tick mark were equal to the perceived horizontal extent of the test element. All responses made in this way were measured by an individual who was blind as to the hypothesis under investigation. The distance between the outside edges of the two marks was measured to the nearest millimeter.

Subjects. The subjects were 126 undergraduate volunteers who had not participated in Experiment 1. The mean age was 18.7 years. As in the previous study, those whose average absolute deviation from the actual size of the practice stimuli was greater than $1.5 \mathrm{~mm}$ were eliminated from further analyses. The remaining sample after this accuracy screening was 118 subjects.

\section{Results and Discussion}

The results of Experiment 2 are shown in Figure 5. The first thing to note is that, as expected, the prototypical illusion magnitude was much larger; it was actually $60 \%$ larger (averaging $1.35 \mathrm{~mm}$ as compared with the $0.8 \mathrm{~mm}$ of Experiment 1). This amounts to a $6.1 \%$ illusion, which is similar in magnitude to that obtained by Coren and Girgus (1972), who used a standard Ebbinghaus configuration and a similar measuring technique. The difference in illusion magnitude between Experiments 1 and 2 (collapsed across the four stimulus types) was statistically significant $(z=3.21, p<.01)$, confirming previous observations that the method of reproduction tends to produce greater illusion magnitude than the selection from a graded series (Coren \& Aks, 1990; Coren \& Girgus, 1972).

When we consider the illusion magnitude for the four stimulus types, we find that the prototype and the same and near categories all produced significant illusions $[t(117)=6.22, t(117)=5.18$, and $t(117)=4.04$, respectively; all $p \mathrm{~s}<.001]$. For the different-category inducers, however, the magnitude of the illusion was not

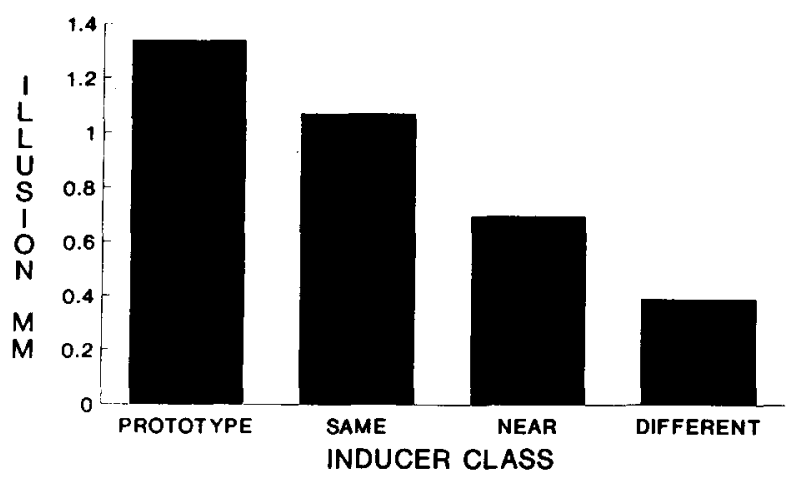

Figure 5. Data from Experiment 2 (using the method of reproduction), showing the magnitude of the size contrast illusion as a function of the degree of conceptual similarity between test and inducing stimuli. Illusion magnitude is defined as the difference between two judged extents: the test stimulus surrounded by small inducers versus the same-size test stimulus surrounded by large inducers. significant, although it was close $[t(117)=1.77, p=$ .08 ]. This was probably due to the fact that although the illusion magnitude remained about the same as that observed for Experiment 1, the variability was greater for the method of reproduction (standard errors averaged $0.32 \mathrm{~mm}$ for method of reproduction, compared with 0.11 for selection from a graded series).

It is clear from Figure 5 that there was greater separation among the stimulus configurations than we had observed in Experiment 1. Furthermore, the conditions were ordered in a manner consistent with the influence of conceptual similarity. An ANOVA showed that there were significant differences among the groups $[F(3,351)=$ $4.34, p<.01]$.

Planned paired comparisons showed that the prototype inducers produced more illusion than the near-category and different-category inducers $[t(117)=2.22, p<.05$, and $t(117)=3.07, p<.01$, respectively], and that the same-category inducers produced more contrast than the different-category inducers $[t(117)=2.43, p<.05]$. Most importantly for the hypothesis under consideration, the linear trend for the groups, ordered according to visual and conceptual distance of inducer and test element, was significant $[F(1,351)=12.96, p<.01]$. The nonparametric Kendall coefficient of concordance again verified that there was a significant and consistent ordering of the illusion magnitudes, with illusion strength decreasing as the conceptual distance between test and inducer grew larger $\left[W=.05, \chi^{2}(3)=21.39, p<.001\right]$.

\section{EXPERIMENT 3}

Although Experiments 1 and 2 seem to confirm that the degree of obtained size contrast is determined by the degree of conceptual similarity between the test and inducing stimuli, a potential criticism of this interpretation is that we did not vary conceptual similarity independently of geometric similarity. It might be argued that these results simply extend the earlier finding that size contrast varies with the geometric similarity between test and inducing elements (Coren \& Miller, 1974). At the theoretical level, we do not think that this problem is as severe as it might first appear to be. We would like to interpret geometric similarity as a special case of the more general continuum of conceptual or semantic similarity. This position has some merit when one considers that the forms that are typically used in studies of geometric similarity belong to the conceptual category of abstract and unfamiliar forms (i.e., shapes that are difficult to name). Although researchers design these stimuli with the implicit assumption that they are "novel" shapes, in truth, all subjects have had considerable experience with this class of object, ranging from their experiences with modern art, architecture, advertising, and their own "doodling." It is therefore probably a mistake to believe that it is possible to extract the pure "geometry" from the pure "meaning" of any picture. Balls are round in shape in order to support their function of being rolled, thrown, 
and caught easily. Objects with similar geometry will tend, therefore, to have similar functions and meaning to the adult perceiver.

At the methodological level, the experimenter who would like to clarify this issue is faced with several difficult problems in trying to tease the conceptual and geometric factors apart. To begin, one would have to measure geometric similarity independently of conceptual category. Theories of visual form perception have still not provided us with a measure that can be applied to pictures of objects in anything but an ad hoc way. The alternative, which would be to have subjects judge geometric similarity subjectively, only invites subjects' implicit judgments of conceptual similarity to contaminate their ratings of geometric similarity.

One solution to this problem might be to find a single figure that could be interpreted as belonging to two different conceptual categories, depending upon viewing conditions or perceptual set. If we could use the same figure as both a prototype inducer and its alternate configuration as a different-category inducer, we would be holding many geometric and figural factors constant while still testing the effects of conceptual category membership. Fortunately, we were able to develop such a figure.

\section{Method}

Stimuli. The basic stimulus array is shown in Figure 6A, which shows the large inducer configuration containing a stylized cartoon of a man in a top hat, wearing a bow tie, with part of his tuxedo front visible below the tie. We call this configuration the "magician." The central test stimulus and the inducers are identical, so this is clearly a prototype configuration.

Figure 6B shows the large inducer segment of conceptually different stimuli. Here we have the same magician as the central test
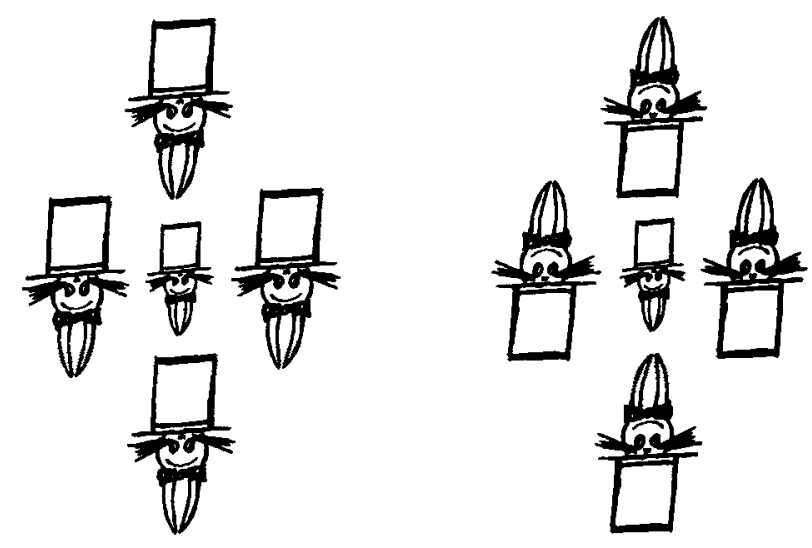


Figure 6. (A) The prototype configuration in which the test stimulus (a cartoon magician) is surrounded by identical stimuli differing only in size. (B) The situation in which test and inducers are drawn from different conceptual categories (magician surrounded by rabbits). The figures that are seen as rabbits are actually geometrically identical to those seen as magicians, differing only in orientation, as can be seen by inverting this array and noting that all of the magicians turn into rabbits and vice versa. stimulus, surrounded by images of a rabbit peeking out of a top hat. These inducing stimuli are no longer from the conceptual category of "human faces," so we are clearly looking at a different conceptual category array.

The value of these configurations as a test of geometric versus conceptual similarity comes from the fact that both the magician and the rabbit are physically identical. This can be seen by inverting Figure 6 . Now Figure $6 \mathrm{~A}$ becomes a rabbit surrounded by identical rabbits, and Figure $6 \mathrm{~B}$ becomes a rabbit surrounded by magicians. Although the elements of these stimuli are physically identical, their interpretation as a rabbit or magician depends only upon their orientation.

The test extent was chosen to be the width of the face of the central magician or rabbit (not counting whiskers or eyelashes). The horizontal extent of the central test face at its widest point was $15 \mathrm{~mm}$. The corresponding dimension for the large inducer was $25 \mathrm{~mm}$ and for the small was $5 \mathrm{~mm}$. As in Experiment 2, there was a measurement line $85 \mathrm{~mm}$ in length and $3 \mathrm{~mm}$ wide, with a $10-\mathrm{mm}$ vertical stop at the far left end on each page. The line was placed $1 \mathrm{~cm}$ from the bottom edge of the sheet containing each test stimulus and $15 \mathrm{~mm}$ from the left edge.

The stimuli were prepared in booklets, each one containing only one central prototype (either rabbit or magician), with all four categories of inducers (large vs. small, prototype vs. different category). Each page of the booklet consisted of a single stimulus configuration. In addition to the size contrast stimuli, three practice stimuli were prepared for each stimulus set. The practice stimuli matched the prototype, but without any inducers. The four practice stimuli were 12,15 , and $18 \mathrm{~mm}$ in horizontal extent.

Procedure. Each subject received only one series of stimuli (all variations associated with a particular prototype test figure). The sequence of presentation consisted of the practice figures, followed by both large and small inducers in either the prototype configuration or the different configuration, and then the alternate configuration with large and small inducers. Only one test configuration appeared on any one page.

Printed instructions were used to establish a consistent perceptual set, in order to maintain a perception of the two orientations as "magician" or "rabbit." The instructions referred to a cartoon version of "Houdini, The Great Magician" or "Bunny, The Magician's Rabbit." Individual configurations were introduced by statements such as (for the magician) "On the next pages you will find Houdini, The Great Magician, surrounded by other magicians large and small, who look a lot like him, except for their size." Or "on the next pages you will find Houdini, The Great Magician, surrounded by some of his rabbits, the ones that he pulls from a hat. He will be surrounded by large and small rabbits." Later interviews with some of the subjects suggested that virtually all were unaware that the configurations of rabbit and magician were the same.

The procedure was similar to that of Experiment 2. The subjects were instructed to indicate the width of the face of either the rabbit or the magician. As before, this was to be done by placing a tick mark, so that the distance between the left end of the line (which contained the vertical stop) and the pencil mark was equal to the perceived horizontal extent. Also, as in the previous experiment, all responses made in this way were measured by an individual who was blind as to the hypothesis under investigation. The distance between the outside edges of the two marks was measured to the nearest millimeter.

Subjects. The subjects were 300 undergraduate student volunteers who were assessed in group settings. Mean age was 18.6 years. All the subjects were naive as to the purpose of the experiment and none had participated in either of the previous experiments.

\section{Results and Discussion}

The results of Experiment 3 showed a significant size contrast illusion for the prototype condition (magician sur- 
rounded by magicians or rabbits surrounded by rabbits), averaging $0.36 \mathrm{~mm}[t(299)=3.56, p<.001]$. This amounts to a distortion of $2.4 \%$, and is therefore somewhat smaller than that obtained in the other experiments. One contributing factor may have been that the central test stimulus was a bit smaller ( 15 vs. $22 \mathrm{~mm}$ ), which tends to reduce the illusion magnitude in percentage terms (Coren \& Girgus, 1978).

Although the prototype configuration showed the expected size contrast, the illusion for the different category configurations (magician surrounded by rabbits or rabbits surrounded by magicians), showed a size contrast illusion of only $0.07 \mathrm{~mm}(0.5 \%$ distortion), which is not statistically different from zero $[t(299)=0.62]$. The magnitude of the illusion obtained for the prototype inducers was significantly greater than that for the inducers from different conceptual categories $[t(299)=2.10, p<.05]$. The importance of this latter comparison is that the two size contrast illusion magnitudes differed, despite the fact that each of the inducing sets contained exactly the same geometric elements. The only difference is that by changing the orientation of the figures and by using a perceptual set, we made one set of inducers appear to be from a different semantic category than the test stimulus.

\section{EXPERIMENT 4}

Although in Experiment 3 we used figures composed of the same geometric elements but varying in conceptual category, because of our manipulation of the orientation of the figures, it might be argued that there are still differences in the geometry of the two categories of stimuli. Thus, some visual aspects, in addition to the semantic identity of the stimuli, still differed between the two arrays. To control for this possibility, an additional study was conducted in which the basic geometric elements of the figures in Experiment 3 were preserved, but in which inversion of the inducers relative to the test element could take place without altering the conceptual category of the stimuli.

\section{Method}

Stimuli. The basic stimulus array for this control study is shown in Figure 7A, which shows the large-inducer configuration. Notice that each of the individual stimuli contain the same schematic geometric elements of the magician-rabbit figure used in Experiment 3 . Thus, each array contains a rectangle (approximating the hat), a circle (corresponding to the head), and a triangle (approximating the bow and ears or the bow tie and lapels). The orientation shown in Figure 7A is thus a control for the "magician" array shown in Figure $6 \mathrm{~A}$, and because the central test stimulus and the inducers are identical, this is clearly a prototype configuration. Figure 7B shows the inducers inverted so that the geometric relations now approximate those of the "rabbit" inducers in Figure 6B. Because of the simple geometric shapes used in this control experiment, it is obvious to the observer that there is no shift in semantic category; rather, Figures 7A and 7B are seen simply as stimuli surrounded by similar stimuli that may differ in orientation. Thus, this configuration can serve as a control for the conceptually different arrays in Figure 6B.

The test extent was chosen to be the width of the central circle corresponding to the head of the central magician or rabbit in Ex-

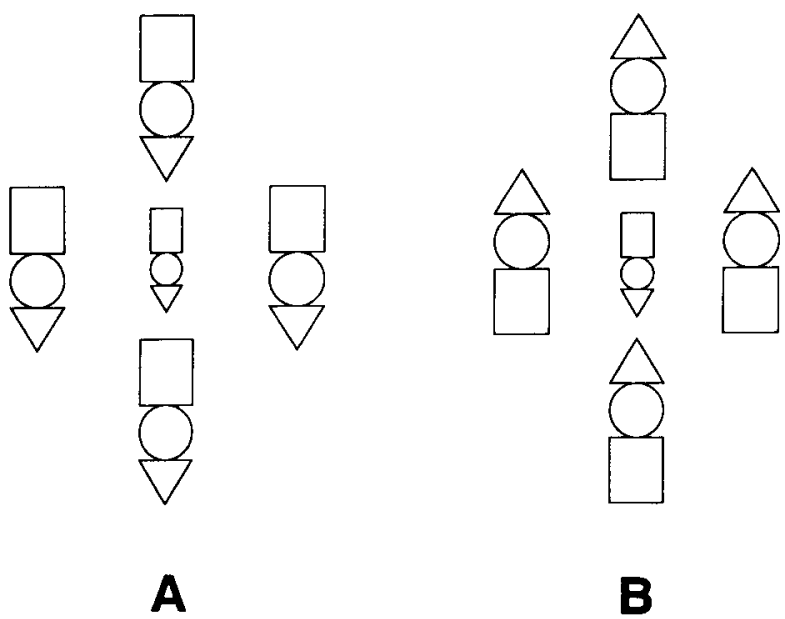

Figure 7. (A) A prototype configuration that was used in Experiment 4 as a control configuration for the stimulus in Figure 6A, where the test stimulus is surrounded by identical stimuli differing only in size. (B) The control stimulus for Figure 6B, where the inducers are inverted relative to the test figure but still are obviously from the same conceptual category.

periment 3. As in the previous study, the horizontal extent of the central test circle at its widest point was $15 \mathrm{~mm}$. The corresponding dimension for the large inducer was $25 \mathrm{~mm}$ and for the small was $5 \mathrm{~mm}$. As in Experiments 2 and 3, there was a measurement line $85 \mathrm{~mm}$ in length and $3 \mathrm{~mm}$ wide, with a $10-\mathrm{mm}$ vertical stop at the far left end on each page. The line was placed $1 \mathrm{~cm}$ from the bottom edge of the sheet containing each test stimulus and $15 \mathrm{~mm}$ from the left edge.

As in Experiment 3, the stimuli were prepared in booklets, each one containing only one central prototype (either with the rectangle at the top, as in Figure 7A, or with this test figure inverted), with all four categories of inducers (large vs. small, same orientation of test and inducer vs. different). Each page of the booklet consisted of a single stimulus configuration. In addition to the size contrast stimuli, three practice stimuli were prepared for each stimulus set. The practice stimuli matched the prototype, but without any inducers. The four practice stimuli were 12,15 , and $18 \mathrm{~mm}$ in horizontal extent.

Procedure. Following the methodology of Experiment 3, each subject received only one series of stimuli (all variations associated with a particular prototype test figure). The sequence of presentation consisted of the practice figures, followed by both large and small inducers in either the prototype configuration or the different configuration, and then the alternate configuration with large and small inducers. Only one test configuration appeared on any one page.

The procedure was similar to that of Experiment 3 . The subjects were instructed to indicate the width of the central circle (which geometrically corresponded to the face of either the rabbit or the magician in Experiment 3). As before, this was to be done by placing a tick mark, so that the distance between the left end of the line (which contained the vertical stop) and the pencil mark was equal to the perceived horizontal extent. Also, as in the previous experiment, all responses made in this way were measured by an individual who was blind as to the hypothesis under investigation. The distance between the outside edges of the two marks was measured to the nearest $0.5 \mathrm{~mm}$.

Subjects. The subjects were 230 undergraduate student volunteers who were assessed in group settings. Mean age was 18.9 years. All the subjects were naive as to the purpose of the experiment. 


\section{Results and Discussion}

As in the previous experiments, the results of Experiment 4 showed a significant size contrast illusion for the prototype condition (test configuration surrounded by same-orientation inducers as in Figure $7 \mathrm{~A}$ ), with a mean illusion of $0.45 \mathrm{~mm}[t(229)=4.53, p<.001]$. This amounts to a distortion of $3.0 \%$, and is therefore marginally larger than the 2.4\% distortion in Experiment 3 . The difference between the outcome of this experiment and the previous one is that the different configuration (test stimulus surrounded by inverted inducers) also produced a significant illusion with a mean of $0.47 \mathrm{~mm}$ $[t(229)=4.07, p<.001]$. This illusion magnitude is virtually identical to that of the prototype configuration and there is no significant difference in the two illusion strengths $[t(229)=0.07$, n.s. $]$.

Thus, both the prototype and the inverted configuration showed the expected size contrast effects. There was no difference in the magnitude of these effects for the two types of configurations, so it seems likely that we can rule out any confounds based upon changing geometric relations as explanations for the differences observed in Experiment 3.

\section{GENERAL DISCUSSION}

Taken together, the results of these four experiments strongly support the notion that semantic category membership is an important factor in predicting size contrast. In Experiments 1, 2, and 3, when the inducing and test elements were visually and taxonomically identical (the prototype condition), illusion magnitude was at its greatest. However, when the inducing elements were no longer visually identical to the test element (same-, near-, and different-category conditions, in Experiments 1 and 2), the magnitude of the illusion seemed to depend upon the semantic similarity between test and inducing elements.

Perhaps the most compelling finding comes from Experiment 3, which allowed the separation of geometric similarity from that of conceptual similarity. In Experiment 3, physically identical elements were used in two conditions, differing only in the orientation in which the elements were presented. By altering the orientation of the figure and by inducing a different perceptual set, it was possible to change the conceptual category membership of an object while keeping the physical elements invariant. If shape similarity was the principal factor, as suggested by Coren and Miller (1974), then there should have been no difference between these two configurations. Instead, the results should have been as we observed in Experiment 4, in which the orientation of the stimuli was varied but there was no shift in conceptual category. Here, there was no difference in illusion magnitude across the stimulus variants. However, the fact that the different category array produced a significantly smaller illusion than the prototype array in Experiment 3, confirms the conclusion that the semantic similarity between test and in- ducing stimuli is an important factor in the magnitude of size contrast. The absence of differences as a function of orientation of the inducers in Experiment 4 rules out possible geometric confounds.

This finding places an important constraint on theories of size contrast. All theories to date have invoked the concept of the stimulus context as a critical factor in making predictions about whether or not size contrast will occur. The only aspect to be considered has traditionally been the average size of the stimuli (inducers) surrounding the judged (test) object, and this mean size is said to be taken as a reference by the subject for making judgments about the test element (Helson, 1964; Restle, 1971; Wilson \& Pressey, 1988). However, none of the theories have been able to define stimulus context in anything other than operational terms. In other words, the relevant stimulus context is simply taken to be those elements that, when surrounding the test element, cause size contrast to occur. The present finding indicates that context may be defined in an independent way. Specifically, the relevant stimulus context includes those elements that are in the same (or related) taxonomic or conceptual category as the test element. This finding, unlike those of previous studies, is able to rule out a vast array of possible stimuli as contexts and therefore places an important boundary condition on the phenomenon of size contrast.

It is important to note that although the present study employed large numbers of subjects to study a size contrast illusion, we do not believe that the conceptual category effect is dependent on large subject sample sizes. We believe instead that the variability in our data derives from the pencil-and-paper nature of the study and our use of only one measure per subject for each configuration, rather than from the nature of the phenomenon of size contrast. The use of multiple measures per subject and continuously variable size stimuli (or adjustable lines) might provide more sensitive measures of this semantic category effect. If such is the case, it is possible to speculate about other implications of these findings.

One possible extension of this methodology has implications for theories of categorization, concept formation, and semantic hierarchies. For instance, cognitive theories of semantic structure and word meaning all assume that concepts are organized in one way or other (see Medin \& Smith, 1984; Smith, 1980, for reviews). Similar concepts are thought to be stored and processed in the brain in physical locations that are closer together than dissimilar concepts. One implication of the finding of a conceptual influence on size contrast, then, is that the size contrast illusion may be used as a tool to study semantic organization in various populations, including college undergraduate, bilingual, brain-damaged, and developing subjects.

Consider, for instance, the question of whether younger children differ from older children in the way that they structure the relations among novel objects. One view is that children generalize word meanings to novel objects on the basis of shared visual features (Anderson \& 
Prawat, 1983), whereas a competing view is that they first generalize on the basis of common function or use (Nelson, 1988). Subjects of different ages could be tested by comparing the size contrast illusion they perceive for a picture of a common object (e.g., a broom) surrounded by objects with similar features but different functions (e.g., various shovels and spades) and for similar functioning objects with different features (e.g., various vacuum cleaners). This method would have an advantage over word-naming paradigms because subjects require no special training or skill (e.g., making speeded naming responses). It also has an advantage over sorting tasks because it is indirect. In such a methodology, subjects would not be asked overtly to consider the semantic nature of the stimuli; however, their response patterns will give us a clue as to whether stimuli are in the same or different conceptual or semantic categories simply by the magnitude of the size contrast effects elicited.

\section{REFERENCES}

Anderson, A. L., \& Prawat, R. S. (1983). When is a cup not a cup? A further examination of form and function in children's labeling responses. Merrill-Palmer Quarterly, 29, 375-385.

COREN, S. (1971). A size contrast illusion without physical size difference. American Journal of Psychology, 84, 565-566.

Coren, S., \& AKs, D. J. (1990). Moon illusion in pictures: A multimechanism approach. Journal of Experimental Psychology: Human Perception \& Performance, 16, 365-380.

COREN, S. \& Girgus, J. S. (1972). A comparison of five methods of illusion measurement. Behavior Research Methods \& Instrumentation, 4, 240-244.

COREN, S., \& GiRgus, J. S. (1978). Seeing is deceiving: The psychology of visual illusions. Hillsdale, NJ: Erlbaum.

Coren, S., Girgus, J. S., Erlichman, H., \& Hakstian, A. R. (1976). An empirical taxonomy of visual illusions. Perception \& Psychophysics, 20, 129-137.

Coren, S., \& Hoy, V. S. (1986). An orientation illusion analog to the rod and frame: Relational effects in the magnitude of the distortion. Perception \& Psychophysics, 39, 159-163.

COREN, S., \& Miller, J. (1974). Size contrast as a function of figural similarity. Perception \& Psychophysics, 16, 355-357.

COREN, S., \& PORAC, C. (1978a). Iris pigmentation and visual-geometric illusions. Perception, 7, 473-478.

Coren, S., \& Porac, C. (1978b). A new analysis of life-span age trends in visual illusions. Developmental Psychology, 14, 193-194.

Coren, S., Ward, L. M., Porac, C., \& Fraser, R. (1978). The effect of optical blur on visual-geometric illusions. Bulletin of the Psychonomic Society, 11, 390-392.

Foltz, G. S., \& Poltrock, S. E. (1984). Mental comparison of size and magnitude: Size congruity effects. Joumal of Experimental Psychology: Learning, Memory, \& Cognition, 10, 442-453.

GIRGUS, J. S., \& COREN, S. (1982). Assimilation and contrast illusions: Differences in plasticity. Perception \& Psychophysics, 32, 555-561.

Girgus, J. S., Coren, S., \& AGdern, M. (1972). The interrelationship between the Ebbinghaus and Delboef illusions. Journal of Experimental Psychology, 95, 453-455.

Helmholtz, H. voN (1866). Handbuch der physiologischen Optik. Hamburg \& Leipzig: Voss.

HELSON, H. (1964). Adaptation level theory: An experimental and systematic approach to behavior. New York: Harper.

Holyoak, K. J., Dumais, S. T., \& Moyer, R. S. (1979). Semantic association effects in a mental comparison task. Memory \& Cognition, 7, 303-313.

IRWIN, D. I., \& LUPKER, S. J. (1983). Semantic priming of pictures and words: A levels of processing approach. Journal of Verbal Learning \& Verbal Behavior, 22, 45-60.
JORDAN, K., \& ENGLISH, P. W. (1989). Simultaneous sampling and length contrast. Perception \& Psychophysics, 46, 546-554.

Jordan, K., \& Schiano, D. J. (1986). Serial processing and the parallellines illusion: Length contrast through relative spatial separation of contours. Perception \& Psychophysics, 40, 384-390.

JORDAN, K., \& UHLARIK, J. (1986). Length contrast in the Müller-Lyer figure: Functional equivalence of temporal and spatial separation. Perception \& Psychophysics, 39, 267-274.

LA HEII, W. (1988). Components of Stroop-like interference in picture naming. Memory \& Cognition, 16, 400-410.

LA Heis, W., \& Dirkx, J. (1990). Categorical interference and associative priming in picture naming. British Journal of Psychology, 81, 511-525.

LUPKER, S. J. (1979). The semantic nature of response competition in the picture-word interference task. Memory \& Cognition, 7, 485-495.

LUPKER, S. J. (1988). Picture naming: An investigation of the nature of categorical priming. Journal of Experimental Psychology: Learning, Memory, \& Cognition, 14, 444-455.

Marschark, M., \& Paivio, A. (1981). Congruity and the perceptual comparison task. Journal of Experimental Psychology: Human Perception \& Performance, 7, 290-308.

Massaro, D. W., \& Anderson, N. H. (1971). Judgmental model of the Ebbinghaus illusion. Journal of Experimental Psychology, 89, 147-151.

Medin, D. L., \& Smith, E. E. (1984). Concepts and concept formation. Annual Review of Psychology, 35, 113-138.

Nelson, K. (1988). Where do taxonomic categories come from? $\mathrm{Hu}^{-}$ man Development, 31, 3-10.

Porac, C., \& Coren, S. (1981). Life-span age trends in the perception of the Müller-Lyer: Additional evidence for the existence of two illusions. Canadian Journal of Psychology, 35, 58-62.

Porac, C., Coren, S., Girgus, J. S., \& Verde, M. (1979). Visualgeometric illusions: Uni-sexed phenomena. Perception, 8, 401-412.

Posnansky, C. J., \& RAYNER, K. (1977). Visual-feature and response components in a picture-word interference task with beginning and skilled readers. Journal of Experimental Child Psychology, 24, $440-460$.

RAYNER, K., \& SPRINGER, C. J. (1986). Graphemic and semantic similarity effects in the picture-word interference task. British Joumal of Psychology, 77, 207-222.

Restle, F. (1971). Visual illusions. In M. H. Appley (Ed.), Adaptation level theory (pp. 55-69). New York: Academic Press.

RosINSKI, R. R. (1975). Picture-word interference is semantically based. Child Development, 48, 643-647.

Shulman, G. L. (1991, November). Attentional modulation of size contrast. Paper presented at the meeting of the Psychonomic Society, San Francisco, CA.

SMITH, E. E. (1980). Organization of factual knowledge. Nebraska Symposium on Motivation, 28, 163-209.

Sperber, R. D., McCauley, C., Ragain, R., \& Weil, C. M. (1979). Semantic priming effects on picture and word processing. Memory \& Cognition, 7, 339-345.

TIPPER, S. P. (1985). The negative priming effect: Inhibitory priming by ignored objects. Quarterly Journal of Experimental Psychology: Human Experimental Psychology, 37A, 571-590.

TIPPER, S. P., DRIVER, J. (1988). Negative priming between pictures and words in a selective attention task: Evidence for semantic processing of ignored stimuli. Memory \& Cognition, 16, 64-70.

WALlaCH, H. Floor, L. (1971). The use of size matching to demonstrate the effectiveness of accommodation and convergence as cues for distance. Perception \& Psychophysics, 10, 423-428.

Weintraub, D. J., \& SchNeck, M. K. (1986). Fragments of Delboeuf and Ebbinghaus illusions: Contour/context explorations of misjudged circle size. Perception \& Psychophysics, 40, 147-158.

Wilson, A. E., \& Pressey, A. W. (1988). Contrast and assimilation in the Baldwin illusion. Perceptual \& Motor Skills, 66, 195-204.

WUNDT, W. (1894). Lectures on human and animal psychology (J. E. Creighton \& E. B. Titchner, Trans.). London: Swan Sonnenschein.

(Manuscript received May 21, 1992; revision accepted for publication April 26, 1993.) 